\title{
LETTERS
}

\section{Sexism in medical care}

We read Manzoor and Redelmeier's article on sexism in medical care with great interest. ${ }^{1}$ Their article tackles gendered perceptions in medicine, which is a pressing issue in the medical profession and a topic of increasing interest to researchers. The article offers independent strategies that female physicians can use when they are mistaken as nurses or other health care professionals in the clinical setting. Although well thought out, independent strategies can be useful tools for combatting socially constructed perceptions of gender and identity, we worry that the authors have missed the larger problems of sexism in medical care by focusing almost exclusively on physician-patient interactions.

While existing research ${ }^{2,3}$ has shown that mischaracterizations (e.g., unequal naming practice) can feel frustrating and demeaning for female physicians when interacting with patients, research from our team and others ${ }^{4,5}$ has also shown that it is the prevalence of gendered norms and subtle microaggressions between medical colleagues that principally reinforce the perception that female physicians are of a lower status than men and negatively affect their careers and well-being. Manzoor and Redemeier appear to suggest that we hold patients to a higher standard of accountability than male clinicians, given that the single paragraph that discusses clinicianclinician interactions is titled "collegial humour" and puts forth the assumption that when female clinicians are mistaken for something other than a physician by their male colleagues, it is a rare error that should be combatted with good humour. In contrast, research has shown ${ }^{6,7}$ that female physicians regularly experience both subtle and overt forms of discrimination in the context of their medical teams, and we contend that these professional relationships should be the primary focus of efforts to improve equity in medicine.

\section{Jeanna Parsons Leigh PhD}

Assistant professor, Dalhousie University, Halifax, NS

\section{Tom Stelfox MD PhD}

Professor and head, University of Calgary, Calgary, Alta.

Cite as: CMAJ 2020 March 23;192:E322. doi: $10.1503 / \mathrm{cmaj} .74854$

\section{References}

1. Manzoor F, Redelmeier DA. Sexism in medical care: "Nurse, can you get me another blanket?". CMAJ 2020;192:E119-20.

2. Wheeler M, de Bourmont S, Paul-Emile K, et al. Physician and trainee experiences with patient bias. JAMA Intern Med 2019;179:1678-85. doi: 10.1001/jamainternmed.2019.4122.

3. DeFilippis EM. Putting the "she" in doctor. JAMA Intern Med 2018;178:323-4.

4. Leigh JP, Grood C, Ahmed SB, et al. Towards gender equity in critical care medicine: a qualitative study of perceived drivers, implications and strategies. Crit Care Med 2019;47:e286-91.

5. Liang R, Dornan T, Nestel D. Why do women leave surgical training? A qualitative and feminist study. Lancet 2019;393:541-9.

6. Ruzycki SM, Freeman G, Bharwani A, et al. Association of physician characteristics with perceptions and experiences of gender equity in an academic internal medicine department. JAMA Netw Open 2019;2:e1915165.

7. Lau ES, Wood MJ. How do we attract and retain women in cardiology? Clin Cardiol 2018;41:264-8.

Competing interests: None declared. 